\title{
Asthma in the Real-World: The Relevance of Gender
}

\author{
Fabio Luigi Massimo Ricciardolo ${ }^{a}$ Stefano Levra $^{a}$ Andrea Elio Sprio $^{b}$ \\ Francesca Bertolini $^{b}$ Vitina Carriero ${ }^{b}$ Fabio Gallo ${ }^{c}$ Giorgio Ciprandi ${ }^{d}$ \\ a Department of Clinical and Biological Sciences, University of Turin, San Luigi Gonzaga University Hospital, Turin, \\ Italy; ${ }^{b}$ Department of Clinical and Biological Sciences, University of Turin, Turin, Italy; ${ }^{\mathrm{C}}$ Department of Health

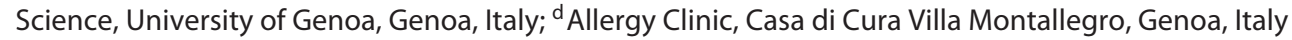

\section{Keywords}

Asthma · Gender · Severity · Control · Lung function · Type 2 inflammation $\cdot$ Real-world setting

\begin{abstract}
Background: The possible gender impact on asthma arouses current and outstanding interest, but few studies addressed this issue in the real-world setting. Objective: This cross-sectional study tested the hypothesis of a potential difference between asthmatic males and females in a real-life setting, such as a third-level asthma clinic. Methods: A total of 499 asthmatic outpatients (301 females and 198 males, mean age 58.25 years) were consecutively visited. The visit included history, asthma control, and severity grade, physical examination, lung function, fractional exhaled nitric oxide assessment, and blood sample for biomarkers. Results: There were more females than males (about 3 of 5). Asthmatic females smoked less ( $p<0.0001)$ than males and had higher $\operatorname{FEV}_{1}(p=0.0022)$ and FVC $(p=0.0004)$ values than asthmatic males. Conclusions: Gender difference was associated with smoking and lung function impairment; thus, this issue should be carefully considered in asthmatic patients in daily clinical practice.

(c) 2020 S. Karger AG, Basel
\end{abstract}

\section{Introduction}

Asthma is a common disease characterized by typical symptoms, reversible bronchial obstruction, bronchial hyperresponsiveness, and airway inflammation. The control of asthma is the cornerstone strategy in the management of patients with asthma as stated by the Global Initiative for Asthma (GINA) document [1]. The asthma control evaluation should be based on a global assessment of respiratory symptoms, lung function, bronchial inflammation, existing comorbidity, risk factors, and compliance and adherence to treatments. The perception of asthma control may be assessed in a standardized way by the Asthma Control Test (ACT) questionnaire. Asthma is also characterized by bronchial inflammation, there are different inflammatory patterns, including type 2 inflammation that may be defined by blood eosinophils, serum IgE, fractional exhaled nitric oxide (FeNO), and allergy documentation [2].

The evaluation of the gender impact on asthma arouses current and outstanding interest and is an interesting research field as recently pointed out [3]. Asthmatic adult

Edited by: H.-U. Simon, Bern. 
Table 1. Demographic and clinical characteristics of the study participants $(n=505)$

\begin{tabular}{|c|c|}
\hline Characteristics & Overall \\
\hline \multicolumn{2}{|l|}{ Gender, $n(\%)$} \\
\hline Males & $198(39.68)$ \\
\hline Females & $301(60.32)$ \\
\hline Mean age $\pm S D$ & $58.25 \pm 15.07$ \\
\hline Mean BMI \pm SD & $26.84 \pm 5.48$ \\
\hline Mean age at onset \pm SD & $37.03 \pm 18.96$ \\
\hline \multicolumn{2}{|l|}{ Smoking, $n(\%)$} \\
\hline Never smoker & $274(54.91)$ \\
\hline Past smoker & $175(35.07)$ \\
\hline Current smoker & $50(10.02)$ \\
\hline Chronic rhinosinusitis & $179(35.45)$ \\
\hline FVC (\% of pred.) & $100.11 \pm 18.08$ \\
\hline $\mathrm{FEV}_{1}(\%$ of pred.) & $83.94 \pm 21.2$ \\
\hline $\mathrm{FEV}_{1} / \mathrm{FVC}$ & $81.78 \pm 13.5$ \\
\hline RV pathologic $(\geq 120 \%)$ & $215(52.18 \%)$ \\
\hline Mean ACT \pm SD & $20.66 \pm 3.66$ \\
\hline Mean FeNO \pm SD & $38.63 \pm 31.25$ \\
\hline \multicolumn{2}{|l|}{ Asthma severity grade } \\
\hline 1 & $63(12.63 \%)$ \\
\hline 2 & $47(9.42 \%)$ \\
\hline 3 & $162(32.46 \%)$ \\
\hline 4 & $115(23.05 \%)$ \\
\hline 5 & $112(22.44 \%)$ \\
\hline Blood eosinophils $>300 / \mathrm{mL}$ & $169(39.67 \%)$ \\
\hline Total IgE (>100 IU) & $151(51.54 \%)$ \\
\hline Type 2 inflammation & $395(81.44 \%)$ \\
\hline \multicolumn{2}{|l|}{ Exacerbations/year } \\
\hline$\leq 1$ & $362(79.04 \%)$ \\
\hline 2 & $42(9.17 \%)$ \\
\hline$>2$ & $54(11.79 \%)$ \\
\hline OSAS & $26(5.15 \%)$ \\
\hline Arterial hypertension & $159(31.49 \%)$ \\
\hline Bronchiectasis & $36(7.13 \%)$ \\
\hline Allergy & $268(53.07 \%)$ \\
\hline Diabetes mellitus & $33(6.53 \%)$ \\
\hline Osteoporosis & $39(7.72 \%)$ \\
\hline Beclo HFA dosage ( $\mu$ g/day) & $300.8 \pm 219.25$ \\
\hline LABA & $388(77.76 \%)$ \\
\hline Oral corticosteroids & $18(3.61 \%)$ \\
\hline Biologics & $53(10.62 \%)$ \\
\hline
\end{tabular}

females have a predominant prevalence: 9.7 versus 5.7\% in males [4] and a predominance of nonallergic asthma [5]. Also, asthmatic females have more severe morbidity than males, such as more visits, hospitalizations, and death rates [6]. Sex hormones may substantially contribute to this gender difference $[7,8]$.

On the other hand, most studies derived from big trials or international surveys that are usually conducted on very selected or multi-ethnic asthmatic populations [9].
Therefore, the present cross-sectional study tested the hypothesis of the potential difference between asthmatic males and females in a real-world setting. The aim was to evaluate the possible association between gender and some demographical, clinical, and functional parameters in a group of asthmatic outpatients visited at a third-level asthma clinic.

\section{Material and Methods}

\section{Patients}

This observational cross-sectional study included 499 asthmatic outpatients. They were referred to an asthma clinic for a specialist visit and were sequentially recruited. Clinical data and patient history were obtained at recruitment. The visit included detailed history, clinical examination, body mass index (BMI) measurement, spirometry, FeNO measurement, skin prick test, blood sampling for eosinophils and total IgE, ACT questionnaire and treatment step level, from step 1 (short-term/periodic use of low dose ICS) to step 5 (at least long-term use of high dose ICS: fluticasone propionate $>500 \mu \mathrm{g}$ plus LABA), according to the GINA document [1].

The diagnosis of asthma was performed considering the history of typical symptoms and the documented demonstration of reversible bronchial obstruction, after bronchodilation testing and/or methacholine challenge.

Continuous variables were given as means and standard deviations (SD), whereas categorical variables as number and/or percentage of subjects. The gender effect on the demographic and clinical characteristics was screened using logistic or multinomial regression for categorical outcomes and linear regression analysis for continuous outcomes. The likelihood ratio (LR) test was used as a test of statistical significance, and the estimated $p$ values were adjusted for multiple comparisons by the Bonferroni correction method. Those models with a gender-associated $p$ value $<0.05$ were then selected for the multivariate analysis, where the gender effect was corrected for age and BMI. Differences with a $p$ value $<$ 0.05 were selected as significant. Data were acquired and analyzed in $\mathrm{R}$ 3.6.2 software environment [10].

\section{Results}

A total of 499 (301 females, 60.32\%) asthmatic outpatients were enrolled in the study. As regards the demographic and clinical characteristics in the whole sample, the mean age was $58.25(\mathrm{SD}=15.07)$ years, BMI 26.84 $(\mathrm{SD}=5.48)$, the age at asthma onset $37.03(\mathrm{SD}=18.96)$ years, $274(54.91 \%)$ were never smokers, $175(35.07 \%)$ past smokers, and $50(10.02 \%)$ current smokers, 179 (35.45\%) had chronic rhinosinusitis, 26 (5.15\%) OSAS, 159 (31.49\%) arterial hypertension, 36 (7.13\%) bronchiectasis, $33(6.53 \%)$ type II diabetes mellitus, and 39 $(7.72 \%)$ osteoporosis (Table 1$)$. As regards lung function, 
Table 2. Descriptive statistics and univariate analysis $(n=499)$

\begin{tabular}{|c|c|c|c|c|}
\hline \multirow[t]{3}{*}{ Characteristics } & \multicolumn{2}{|c|}{ Descriptive statistics } & \multicolumn{2}{|l|}{ Regression analysis } \\
\hline & \multicolumn{2}{|l|}{ Gender } & \multirow[b]{2}{*}{ estimated OR (95\% CI) } & \multirow[b]{2}{*}{$p$ value } \\
\hline & male & female & & \\
\hline Smoking* & & & & $<0.0001$ \\
\hline Never smokers & $78(39.39 \%)$ & $196(65.12 \%)$ & 1 & \\
\hline Past smokers & $95(47.98 \%)$ & $80(26.58 \%)$ & $0.34(0.23 \text { to } 0.5)^{\S}$ & \\
\hline Current smokers & $25(12.63 \%)$ & $25(8.31 \%)$ & $0.4(0.22 \text { to } 0.73)^{\S}$ & \\
\hline Asthma severity grade & & & & 0.9999 \\
\hline 1 & $24(12.12 \%)$ & $39(12.96 \%)$ & 1 & \\
\hline 2 & $24(12.12 \%)$ & $23(7.64 \%)$ & $0.59(0.27 \text { to } 1.27)^{\S}$ & \\
\hline 3 & $67(33.84 \%)$ & $95(31.56 \%)$ & $0.87(0.48 \text { to } 1.59)^{\S}$ & \\
\hline 4 & $43(21.72 \%)$ & $72(23.92 \%)$ & $1.03(0.55 \text { to } 1.94)^{\S}$ & \\
\hline 5 & $40(20.2 \%)$ & $72(23.92 \%)$ & $1.11(0.58 \text { to } 2.1)^{\S}$ & \\
\hline Oral corticosteroids & $10(5.05 \%)$ & $8(2.66 \%)$ & $0.51(0.19 \text { to } 1.32)^{\diamond}$ & 0.9999 \\
\hline Beclo HFA dosage & $296.97(217.49)$ & $303.32(220.73)$ & $6.35(-33.1 \text { to } 45.81)^{\#}$ & 0.9999 \\
\hline Biologics & $18(9.09 \%)$ & $35(11.63 \%)$ & $1.32(0.73 \text { to } 2.44)^{\diamond}$ & 0.9999 \\
\hline LABA & $149(75.25 \%)$ & $239(79.4 \%)$ & $1.27(0.83 \text { to } 1.94)^{\diamond}$ & \\
\hline Exacerbations/year & & & & 0.3893 \\
\hline$\leq 1$ & $147(84.97 \%)$ & $215(75.44 \%)$ & $1^{\S}$ & \\
\hline 2 & $8(4.62 \%)$ & $34(11.93 \%)$ & $2.91(1.31 \text { to } 6.46)^{\S}$ & \\
\hline$>2$ & $18(10.4 \%)$ & $36(12.63 \%)$ & $1.37(0.75 \text { to } 2.5)^{\S}$ & \\
\hline Chronic rhinosinusitis & $73(36.87 \%)$ & $106(35.22 \%)$ & $0.93(0.64 \text { to } 1.35)^{\diamond}$ & 0.9999 \\
\hline Blood eosinophils $>300$ & $80(48.48 \%)$ & $89(34.1 \%)$ & $0.55(0.37 \text { to } 0.82)^{\diamond}$ & 0.0923 \\
\hline Total IgE $>100$ IU & $65(59.09 \%)$ & $86(46.99 \%)$ & $0.61(0.38 \text { to } 0.99)^{\diamond}$ & 0.9999 \\
\hline Type 2 inflammation & $164(84.97 \%)$ & $231(79.11 \%)$ & $0.67(0.41 \text { to } 1.08)^{\diamond}$ & 0.9999 \\
\hline OSAS & $9(4.55 \%)$ & $17(5.65 \%)$ & $1.26(0.56 \text { to } 3.01)^{\diamond}$ & 0.9999 \\
\hline Arterial hypertension & $58(29.29 \%)$ & $101(33.55 \%)$ & $1.22(0.83 \text { to } 1.8)^{\diamond}$ & 0.9999 \\
\hline Bronchiectasis & $14(7.07 \%)$ & $22(7.31 \%)$ & $1.04(0.52 \text { to } 2.12)^{\diamond}$ & 0.9999 \\
\hline Allergy & $107(54.04 \%)$ & $158(52.49 \%)$ & $0.94(0.66 \text { to } 1.35)^{\diamond}$ & 0.9999 \\
\hline Diabetes mellitus & $11(5.56 \%)$ & $22(7.31 \%)$ & $1.34(0.65 \text { to } 2.93)^{\diamond}$ & 0.9999 \\
\hline Osteoporosis & $16(8.08 \%)$ & $22(7.31 \%)$ & $0.9(0.46 \text { to } 1.78)^{\diamond}$ & 0.9999 \\
\hline Age & $58.41(15.02)$ & $58.15(15.13)$ & $-0.26(-2.97 \text { to } 2.46)^{\#}$ & 0.9999 \\
\hline BMI & $26.81(4.53)$ & $26.86(6.05)$ & $0.05(-1 \text { to } 1.1)^{\#}$ & 0.9999 \\
\hline Age at onset & $36(17.93)$ & $37.68(19.59)$ & $1.68(-1.82 \text { to } 5.18)^{\#}$ & 0.9999 \\
\hline FVC \%pred.* & $95.82(16.58)$ & $103(18.5)$ & $7.18(3.96 \text { to } 10.4)^{\#}$ & 0.0004 \\
\hline $\mathrm{FEV}_{1}$ \%pred.* & $79.32(20.24)$ & $86.98(21.31)$ & $7.66(3.89 \text { to } 11.43)^{\#}$ & 0.0022 \\
\hline $\mathrm{FEV}_{1} / \mathrm{FVC}$ & $82(14.21)$ & $81.64(13.05)$ & $-0.36(-2.99 \text { to } 2.28)^{\#}$ & 0.9999 \\
\hline RV $>120 \%$ pred. & $96(55.81 \%)$ & $119(49.58 \%)$ & $0.78(0.52 \text { to } 1.15)^{\diamond}$ & 0.9999 \\
\hline ACT & $21.19(3.53)$ & $20.33(3.7)$ & $-0.86(-1.54 \text { to } 0.19)^{\#}$ & 0.3437 \\
\hline FeNO & $39.17(28.17)$ & $38.27(33.16)$ & $-0.9(-7.17 \text { to } 5.37)^{\#}$ & 1.0000 \\
\hline
\end{tabular}

Characteristics: the outcome was taken into account. Descriptive statistics: outcome of descriptive statistics, $\%$ and mean with standard deviation were reported for categorical and continuous outcome, respectively. Estimate (95\% CI): linear regression coefficient with 95\% CI (marked with ${ }^{\#}$ ), and odds ratios, estimated using logistic (marked with ${ }^{\diamond}$ ) or multinomial (marked with ${ }^{\S}$ ) regression, were reported. $p$ value: the likelihood ratio $p$ value adjusted for multiple comparisons by the Bonferroni correction method. * Outcomes entered in multivariate analysis (see Statistical Methods for more details). $p$ values $<0.05$ were reported in bold.

the mean percentages of predicted values were: FVC $100.11(\mathrm{SD}=18.08), \mathrm{FEV}_{1} 83.94(\mathrm{SD}=21.2), \mathrm{FEV}_{1} / \mathrm{FVC}$ $81.78(\mathrm{SD}=13.5)$; mean $\mathrm{FeNO}$ was $38.63(\mathrm{SD}=31.25)$. The mean ACT was 20.66 ( $\mathrm{SD}=3.66)$. As regards the asthma severity grade, 63 outpatients $(12.63 \%)$ had grade $1,47(9.42 \%)$ grade $2,162(32.46 \%)$ grade $3,115(23.05 \%)$ grade 4 , and $112(22.44 \%)$ grade $5 ; 362(79.04 \%)$ had $\leq 1$ exacerbation/year, $42(9.17 \%) 2$, and $54(11.79 \%)>2$. As 
regards type 2 inflammation, 169 (39.67\%) had $>300$ blood eosinophils, 151 (51.54\%) total IgE $>100$, and 268 (53.07\%) allergy, in particular, 226 (44.75\%) were polyallergic and 193 (38.22\%) were allergic to perennial allergens (house dust mites and pets). Two hundred and fifteen $(52.18 \%)$ outpatients had abnormal RV. As regards current treatment, 388 (77.76\%) used LABA, 18 (3.61\%) oral corticosteroids, and $53(10.62 \%)$ biologics (omalizumab or mepolizumab); the mean ICS beclomethasoneequivalent dosage was $300.8(\mathrm{SD}=219.25) \mu \mathrm{g}$.

The univariate analysis showed significant gender difference concerning smoking status, $\mathrm{FVC}$, and $\mathrm{FEV}_{1}$, as analytically reported in Table 2 ( $p$ values: $<0.0001,0.0004$, and 0.0022 , respectively). The subsequent multivariate analysis confirmed significant gender association with smoking status, FVC, and $\mathrm{FEV}_{1}$ corrected for age and BMI (LR $p$ values $<0.0001$ ). In particular, past smoking was less likely in female outpatients than in males (OR with $95 \% \mathrm{CI}=0.33 ; 0.22: 0.51$ ). Current smoking was less likely in female outpatients (OR with $95 \% \mathrm{CI}=0.42 ; 0.21$ : $0.83)$. Moreover, higher FVC was more likely in females than in male patients ( $\mathrm{OR}$ with $95 \% \mathrm{CI}=8.07 ; 4.71: 11.42$ ) as well as $\mathrm{FEV}_{1}$ (OR with $95 \% \mathrm{CI}=8.05 ; 4.16$ : 11.94).

\section{Discussion}

The present real-world study demonstrated that there was a clear prevalence of asthmatic females and a significant association of gender with smoking and lung function. On the contrary, there was no significant difference concerning the other considered parameters. The current outcomes are consistent with a recent study conducted in patients with severe asthma and included in the German asthma net cohort [11]. Milger et al. [11] reported a significant difference between asthmatic males and females concerning lung function, namely females had higher values of FEV $1, F V C, \mathrm{MEF}_{25}$, and DLCO. Moreover, females had work limitations. Even though this study was restricted to severe asthma, the findings confirmed that asthmatic females were more numerous than males. This is a wellknown finding, in fact asthma is usually more prevalent in asthmatic females than in males $[4,12]$. However, this difference is likely dependent on the peculiar hormonal pattern, in fact, in prepubertal children, there is a prevalence of males, but there is no significant difference between genders concerning lung function and other clinical parameters $[13,14]$.

Moreover, females had a better lung function than asthmatic males. These authors hypothesized that a pos- sible explanation of this outcome could depend on the higher percentage of patients with smoking history in male compared with female patients. Consistently, the current study confirmed that asthmatic females were more frequently never or past smokers than males. This finding may easily explain the better lung function that has been detected in females, and the negative impact of smoking on lung function is well-known [15].

However, the present real-world study had a main limitation because it was performed cross-sectionally, so further longitudinal studies should be performed to confirm these findings. On the other hand, the real-world setting allowed to represent the daily practice of a third-level asthma clinic, including a wide range of asthma severity.

In conclusion, females with asthma have less propensity to smoke and better lung function than males when evaluated in a real-life setting. On the other hand, there are no clinically relevant differences between genders about asthma control GINA grade as well as inflammatory parameters. Thus, about asthma management in daily clinical practice, it is important to pay attention to gender, mainly concerning the lung function assessment.

\section{Statement of Ethics}

This study was performed in accordance with the Declaration of Helsinki. This human study was approved by the local Ethics Committees of San Luigi Gonzaga University Hospital (Prot. No. $4478 / 2017)$. All adult participants provided written informed consent to participate in this study.

\section{Disclosure Statement}

The authors have no conflicts of interest to declare.

\section{Funding Sources}

No funding was received.

\section{Author Contributions}

F.L.M.R. designed the study and revised the draft; S.L., F.B., and V.C. managed clinical data; A.E.S. and F.G. analyzed the data; G.C. wrote the paper. 


\section{References}

1 Global Initiative for Asthma. GINA guidelines. Global Strategy for Asthma Management and Prevention. Available from: https://www.ginasthma.org/. Last accessed on February 2020

2 Ciprandi G, Tosca MA, Silvestri M, Ricciardolo FL. Inflammatory biomarkers for asthma endotyping and consequent personalized therapy. Expert Rev Clin Immunol. 2017 Jul;13(7):715-21.

3 Raghavan D, Jain R. Increasing awareness of sex differences in airway diseases. Respirology. 2016 Apr;21(3):449-59.

4 Akinbami LJ, Moorman J, Bailey CB, Zahran HS, King M, Johnson CA, et al. Trends in asthma prevalence, health care use, and mortality in the United States, 2001-2010. NCHS Data Brief 2012 May;(94):1-8.

5 Leynaert B, Sunyer J, Garcia-Esteban R, Svanes C, Jarvis D, Cerveri I, et al. Gender differences in prevalence, diagnosis and incidence of allergic and non-allergic asthma: a population-based cohort. Thorax. 2012 Jul; 67(7):625-31.
6 Tam A, Morrish D, Wadsworth S, Dorscheid D, Man SF, Sin DD. The role of female hormones on lung function in chronic lung diseases. BMC Womens Health. 2011 Jun;11(1): 24.

7 Farha S, Asosingh K, Laskowski D, Hammel J, Dweik RA, Wiedemann HP, et al. Effects of the menstrual cycle on lung function variables in women with asthma. Am J Respir Crit Care Med. 2009 Aug;180(4):304-10.

8 Graziottin A, Serafini A. Perimenstrual asthma: from pathophysiology to treatment strategies. Multidiscip Respir Med. 2016 Aug; 11(1):30.

9 Abraham I, Alhossan A, Lee CS, Kutbi H, MacDonald K. 'Real-life' effectiveness studies of omalizumab in adult patients with severe allergic asthma: systematic review. Allergy. 2016 May;71(5):593-610.

10 R Core Team. (2019). R: A language and environment for statistical computing. R Foundation for Statistical Computing, Vienna, Austria. https://www.R-project.org/
11 Milger K, Korn S, Buhl R, Hamelmann E, Herth FJ, Gappa M, et al. Age- and sex-dependent differences in patients with severe asthma included in the German Asthma Net cohort. Respir Med. 2020 Feb;162:105858.

12 Ciprandi G, Gallo F. The impact of gender on asthma in the daily clinical practice. Postgrad Med. 2018 Mar;130(2):271-3.

13 Tosca MA, Silvestri M, Ciprandi G, Rossi GA. Obesity and asthma in Caucasian preschool children: is there a gender difference? Pediatr Allergy Immunol. 2012 Dec;23(8):793-4.

14 Okabe Y, Adachi Y, Itazawa T, Yoshida K, Ohya Y, Odajima H, et al. Association between obesity and asthma in Japanese preschool children. Pediatr Allergy Immunol. 2012 Sep;23(6):550-5.

15 Accordini S, Janson C, Svanes C, Jarvis D. The role of smoking in allergy and asthma: lessons from the ECRHS. Curr Allergy Asthma Rep. 2012 Jun;12(3):185-91. 